\title{
Magnesium-Nickel Alloy for Hydrogen Storage Produced by Melt Spinning Followed by Cold Rolling
}

\author{
Daniel Rodrigo Leiva ${ }^{a *}$, Hevlin Cristina de Almeida Costa ${ }^{\mathrm{b}}$,Jacques Huot ${ }^{\mathrm{c}}$,
}

Tiago Santos Pinheiro ${ }^{\mathrm{b}}$, Alberto Moreira Jorge Jr. ${ }^{\mathrm{b}}$,

Tomaz Toshimi Ishikawa ${ }^{\mathrm{b}}$, Walter José Botta

${ }^{\mathrm{a}}$ Faculdade de Ciências Aplicadas, Universidade Estadual de Campinas - UNICAMP,

Limeira, SP, Brasil

${ }^{\mathrm{b}}$ Departamento de Engenharia de Materiais, Universidade Federal de São Carlos - UFSCar,

São Carlos, SP, Brasil

'Institut de Recherche sur l'Hydrogène, Université du Québec à Trois-Rivières, Trois-Rivières, Québec, Canada

Received: January 7, 2012; Revised: May 10, 2012

\begin{abstract}
Severe plastic deformation routes (SPD) have been shown to be attractive for short time preparation of magnesium alloys for hydrogen storage, generating refined microstructures and interesting hydrogen storage properties when compared to the same materials processed by high-energy ball milling (HEBM), but with the benefit of higher air resistance. In this study, we present results of a new processing route for $\mathrm{Mg}$ alloys for hydrogen storage: rapid solidification followed by cold work. $\mathrm{A}^{\mathrm{Mg}} \mathrm{gg}_{97} \mathrm{Ni}_{3}$ alloy was processed by melt spinning (MS) and by extensive cold rolling (CR). Submitting $\mathrm{Mg}_{97} \mathrm{Ni}_{3}$ ribbons between steel plates to cold rolling has shown to be a viable procedure, producing a thin cold welded foil, with little material waste. The as-processed material presents a high level of [002] fiber texture, a sub microcrystalline grain structure with a high density of defects, and also a fine dispersion of $\mathrm{Mg}_{2} \mathrm{Ni}$ nanoparticles. This refined microstructure allied to the developed texture resulted in enhanced activation and $\mathrm{H}$-sorption kinetics properties.
\end{abstract}

Keywords: hydrogen storage materials, metal hydrides, severe plastic deformation

\section{Introduction}

Hydrogen is considered the ideal energy carrier due to its high energy content, $120 \mathrm{MJ} . \mathrm{kg}^{-1}$, being the highest among the chemical fuels, and to the fact that only water is obtained after its use in a combustion engine or fuel cell. However, finding effective hydrogen storage solutions remains as a key technological challenge to its widespread use.

Metal hydrides can store safely hydrogen in the solid state, avoiding the use of high pressure (gaseous $\mathrm{H}_{2}$ ) or very low temperatures (liquid hydrogen) ${ }^{1}$. Magnesium is a promising material for hydrogen storage because it has low cost and is fairly accessible. Besides this, $\mathrm{MgH}_{2}$ has a high hydrogen capacity, of $7.6 \mathrm{wt} .(\%)$, and very good reversibility and cyclability. However, conventional microcrystalline $\mathrm{Mg}$ reacts with hydrogen with slow kinetics ${ }^{2}$, even at high temperatures such as $400{ }^{\circ} \mathrm{C}$.

Several attempts were made to improve the hydrogen storage properties of $\mathrm{Mg}$ alloys or composites using the benefits of the processing by high-energy ball milling (HEBM), namely the combination of the very high microstructure refinement and the fine dispersion of additives with catalytic action. The obtained nanocrystalline structure, combined to the high surface specific area of the powders, favors fast $\mathrm{H}$-sorption kinetics. Among the

*e-mail: daniel.leiva@fca.unicamp.br additives tested to produce Mg-based nanocomposites by HEBM, the best results were obtained for transition metals ${ }^{3}$, their oxides ${ }^{4}$ or fluorides ${ }^{5}$. In these cases, only a few minutes are needed at $300{ }^{\circ} \mathrm{C}$ or even lower temperatures for full H-sorption.

However, HEBM is a very time and energy consuming processing technique, and produces a material very reactive with air, and consequently it is essential to manipulate it under inert atmosphere ${ }^{6}$. The disadvantages of the use HEBM to prepare Mg-based alloys or composites for hydrogen storage can be avoided by severe plastic deformation (SPD) techniques, as for example, extensive cold rolling ${ }^{7}$ or equal channel angular pressing, ECAP ${ }^{8}$. The application of SPD involves usually short processing times and can produce submicrocrystalline or even nanocrystalline bulk samples, and therefore with superior air-resistance and with fairly good $\mathrm{H}$-sorption properties kinetics when compared to the same milled samples.

Cold rolling has been shown to be a very interesting processing technique for $\mathrm{Mg}$ or its alloys for hydrogen storage. Dufour and Huot have compared the activation and $\mathrm{H}$-sorption properties of $\mathrm{Mg}-2.5 \% \mathrm{Pd}$ mixtures after HEBM or cold rolling ${ }^{7}$. Compared to the milled powders, the laminated sample presented faster activation, similar sorption kinetics, but with the benefit of improved 
air-resistance. The [002] fiber texture developed during rolling was associated with the observed shorter activation time, as verified also for oriented $\mathrm{Mg}$ thin films ${ }^{9}$.

We have been using in the last few years different SPD techniques for the preparation of $\mathrm{Mg}$ and $\mathrm{Mg}$-based alloys aiming hydrogen storage applications. For example, we have tested ECAP, CR, HPT (high-pressure torsion), and $\mathrm{CF}$ (cold forging) as processing routes e.g. ${ }^{10-12}$. Compared to HPT and CF, CR promoted faster activation due to the combination of the high level of [002] texture and good microstructural refinement ${ }^{11}$. In this study, we present a new route to obtain bulk grain-refined $\mathrm{Mg}$ samples, using melt spinning followed by cold rolling. Combining rapid solidification and cold work has shown to be a good strategy to produce $\mathrm{Mg}$ alloy with interesting texture, microstructure and surface area for hydrogen storage, leading to attractive activation and $\mathrm{H}$-sorption kinetics.

\section{Experimental Procedure}

The $\mathrm{Mg}_{97} \mathrm{Ni}_{3}$ (at. (\%)) alloy was prepared by induction melting and subsequently processed by melt spinning under argon atmosphere, using a graphite crucible in a single roller melt-spinning wheel at a tangential wheel speed of $42 \mathrm{~m} / \mathrm{s}$. The injection pressure was 450 mbar and the distance of the vial to the wheel, $0.5 \mathrm{~mm}$. The obtained melt spun ribbons were kept in air for around seven years with no
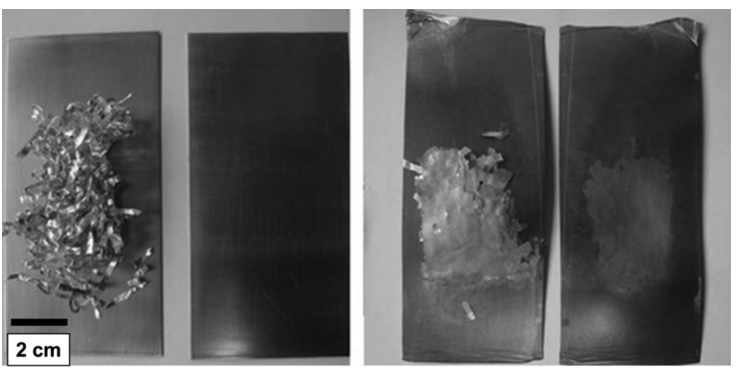

Figure 1. $\mathrm{Mg}_{97} \mathrm{Ni}_{3}$ alloy ribbons before (left) and after (right) cold rolling between stainless steel plates.

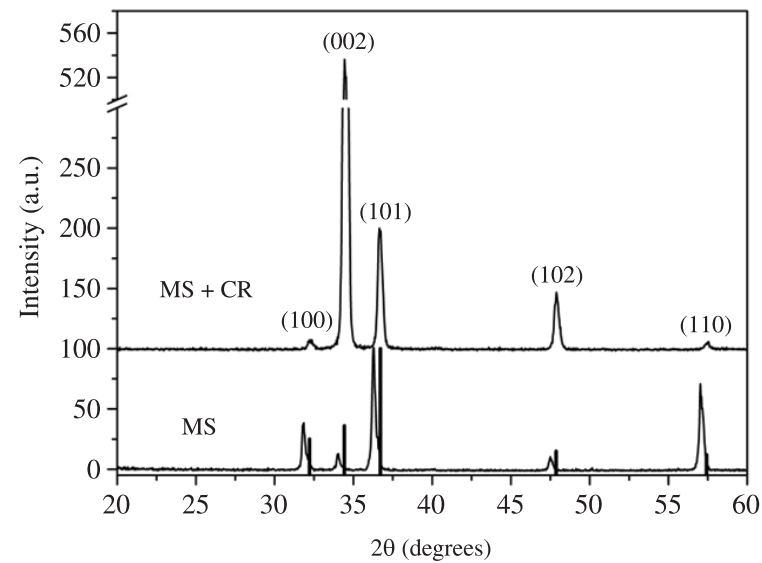

(a) special care to prevent moisture or oxygen contamination. After this long time of air-exposure, the ribbons were confined between stainless steel plates and submitted to several cold rolling passes in a due-reversible FENN rolling mill. Microstructural characterization was carried out by X-ray diffraction (DRX) and transmission electron microscopy (TEM). The XRD patterns were obtained using monochromatic $\mathrm{Cu} \mathrm{K} \alpha$ radiation in a Rigaku diffractometer operating at $40 \mathrm{kV}$ and $40 \mathrm{~mA}$ and equipped with a graphite monochromator. TEM was performed in a FEI TECNAI G2 F20 $200 \mathrm{kV}$ microscope. The H-sorption properties were measured in a home-made Sievert-type apparatus, described in details elsewhere ${ }^{13}$, in static mode. A sample mass of around $100 \mathrm{mg}$ was used. The temperature was fixed in $350{ }^{\circ} \mathrm{C}$ in all measurements. The $\mathrm{H}_{2}$ pressure was of $20 \mathrm{bar}$ for absorption and 0.3 bar for desorption.

\section{Results and Discussion}

Figure 1 presents photographs of the $\mathrm{Mg}_{97} \mathrm{Ni}_{3}$ ribbons before and after CR rolling between stainless steel plates. Several rolling passes were applied until reach the limit lower distance between the rollers. The melt spun ribbons were succesfully consolidated by the occurrence of cold welding into a thin foil of around $100 \mu \mathrm{m}$ thick, keeping the material waste to a minimum. The obtained form of the cold rolled sample is interesting, since it is expected to present some air resistance due to the relatively low surface area to volume ratio (when compared to milled powders), but its thickness is not excessively high to make hydrogen diffusion too difficult ${ }^{2}$.

The XRD patterns of the melt spun ribbons samples before (MS) and after cold rolling (MS + CR) are shown in Figure 2. The intensities in Figure 2 a were normalized to allow a comparison of the texture in the MS and MS + CR conditions. Normalization was done assuming the intensity of the main $\mathrm{Mg}$ peak, (101), being equal to 100 in both XRD patterns. The reference values for magnesium, JCPDS 35-0821, are included in Figure 2a.

Observing the XRD pattern of the $\mathrm{Mg}_{97} \mathrm{Ni}_{3}$ after melt spinning in the Figure $2 \mathrm{a}$, one can see from the relative

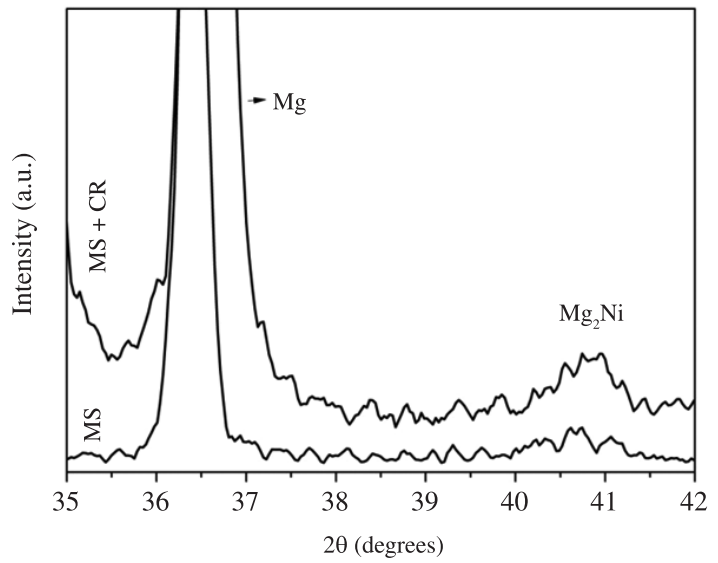

(b)

Figure 2. (a) Normalized XRD patterns of $\mathrm{Mg}_{97} \mathrm{Ni}_{3}$ alloy ribbons before and after cold rolling. The $\mathrm{Mg}$ XRD reference data, JCPDS 35-0821, is included for comparison. (b) Details of the XRD patterns for $2 \theta$ values between 35 and $42^{\circ}$, evidencing $\mathrm{Mg}_{2} \mathrm{Ni}$ precipitation during $\mathrm{CR}$. 
intensities that some texture is introduced during rapid solidification. The diffraction peaks are displaced to the left, indicating the formation of a metastable solid solution of $\mathrm{Ni}$ into the $\mathrm{Mg}$ lattice. The XRD pattern in the MS + CR condition, Figure $2 \mathrm{a}$, shows that the cold rolled material presents a very high level of [002] fiber texture, which has shown to improve the activation kinetics ${ }^{7,9}$. After normalization, the intensity of the (002) peak is 32.9 times higher in the MS + CR sample than in the MS one.

Compared to the melt spun ribbons, the cold rolled sample shows broader XRD peaks, which can be attributed to a reduction in the mean crystallite size and to an important increase in the density of defects ${ }^{10}$. Besides this, after CR the $\mathrm{Mg}$ diffraction peaks are in the reference position, indicating that $\mathrm{Ni}$ precipitated in a second phase after the mechanical processing.

Figure $2 \mathrm{~b}$ shows details of the MS and MS + CR diffraction patterns in the $2 \theta$ region ranging from 35 to $42^{\circ}$. Small XRD peaks due to the equilibrium phase $\mathrm{Mg}_{2} \mathrm{Ni}$ were detected in both samples, but in higher intensity in the cold rolled foil. The low intensity of this peak is due to its small volumetric fraction, since the Ni content of the alloy is low, while the broadness of the peak should be related to its nanocrystalline structure.

Figures 3a, b present STEM images of the $\mathrm{Mg}_{97} \mathrm{Ni}_{3}$ alloy ribbons. The microstructure is considerably refined, with the bigger $\mathrm{Mg}$ grains measuring only a few microns, and with an important fraction of the grains in the sub-micrometric range, Figure $3 \mathrm{a}$. The $\mathrm{Mg}_{2} \mathrm{Ni}$ precipitates are round and finely distributed, Figure $3 \mathrm{~b}$, with diameters of around $20 \mathrm{~nm}$ or even smaller. A similar microstructure was found for Mg-Ni alloys processed by MS, in a recent paper by Bendersky et al. ${ }^{14}$. The authors attributed the improvement in hydrogenation kinetics observed in their study to the catalytic action of the ultrafine $\mathrm{Mg}_{2} \mathrm{Ni}$ precipitates.

Further grain refinement and a large accumulation of defects were obtained with the application of cold work, as seen in Figures 3c, d. A heavily deformed microstructure is seen in Figure $3 c$, in which with small grains or subgrains are delimitated by regions with high dislocation density. In Figure $3 \mathrm{~d}$ individual subgrains are seen, with diameter not higher than $200 \mathrm{~nm}$.

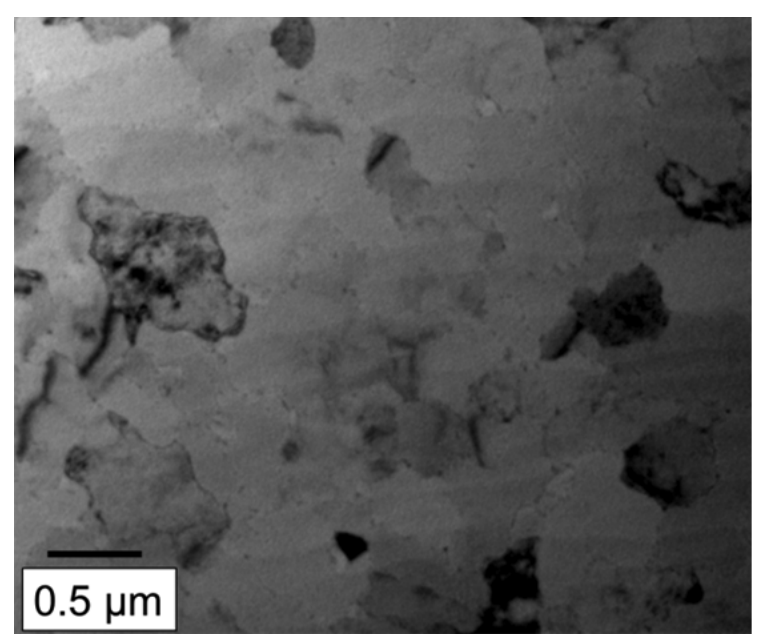

(a)

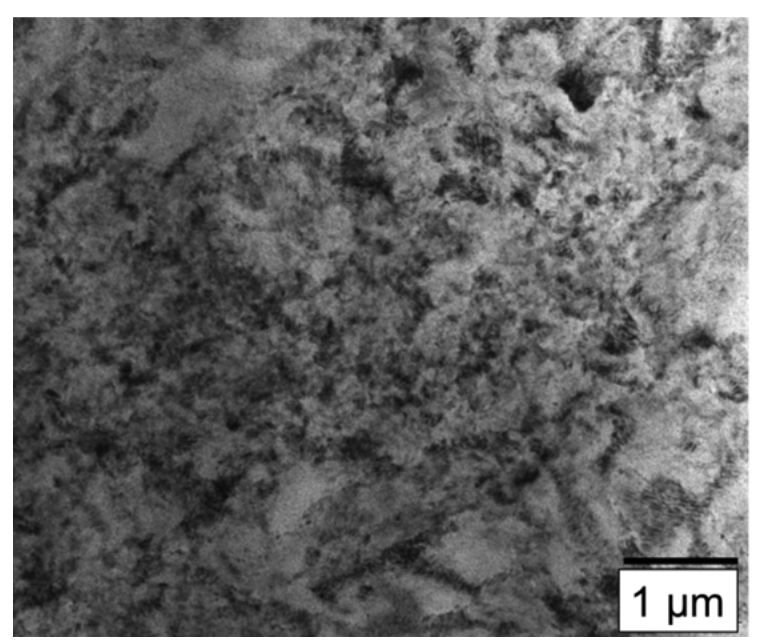

(c)

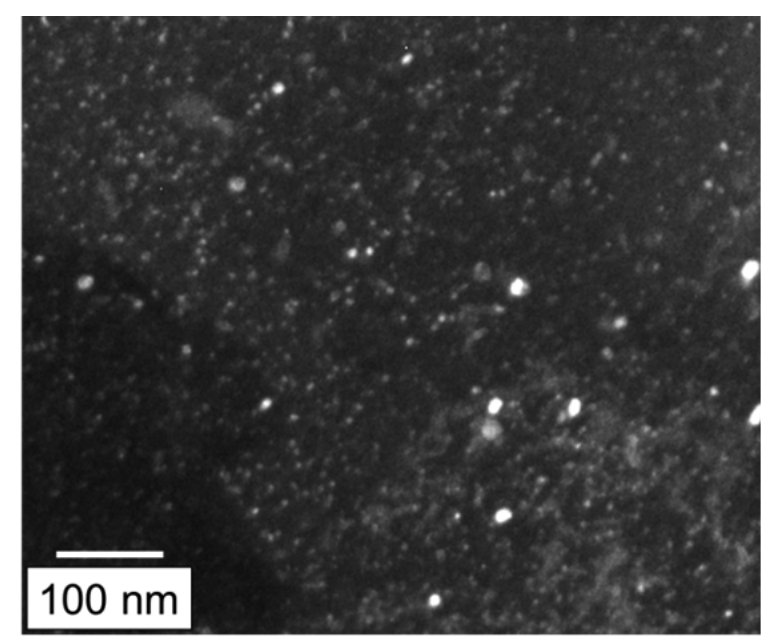

(b)

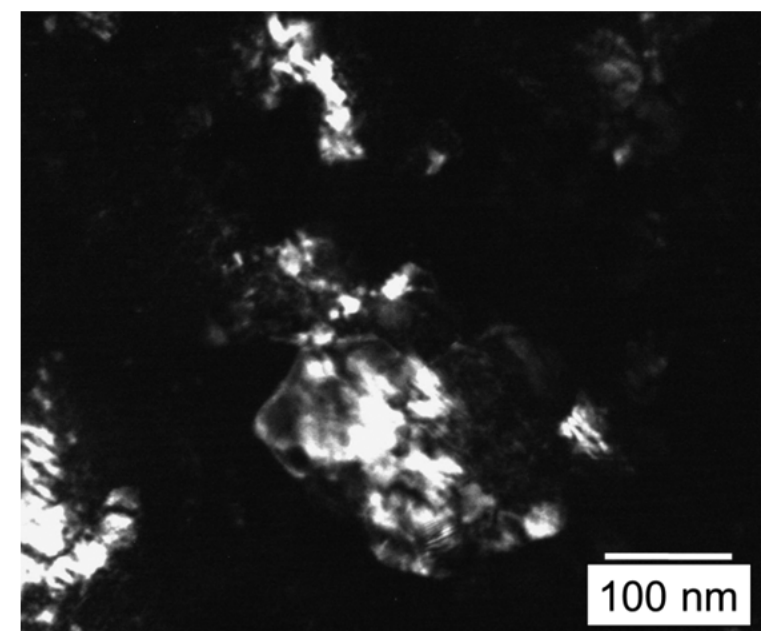

(d)

Figure 3. STEM (a) bright and (b) dark field images of the $\mathrm{Mg}_{97} \mathrm{Ni}_{3}$ melt spun ribbon. TEM (c) bright and (d) dark field images of the cold rolled foil. Note the different magnifications in each case. 




(a)

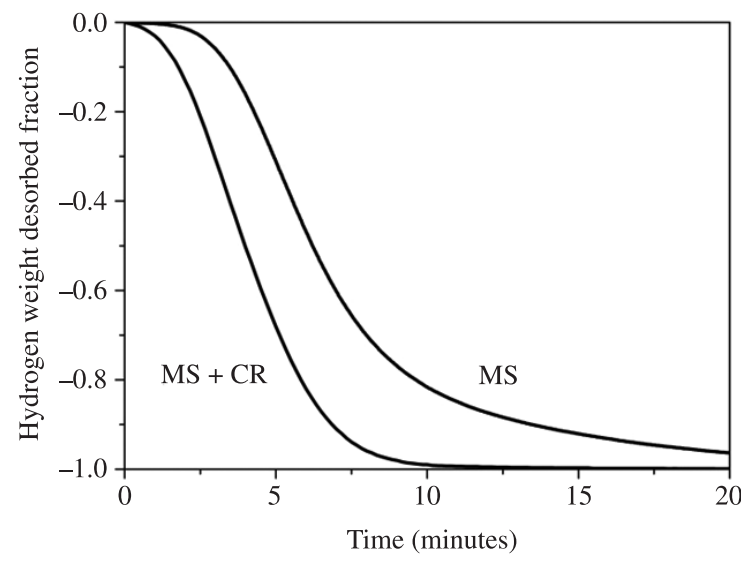

(b)

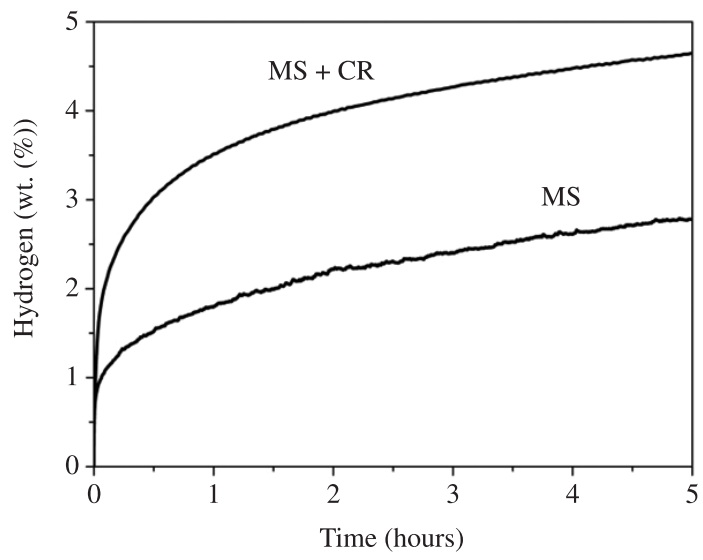

(c)

Figure 4. (a) Activation curves for $\mathrm{Mg}_{97} \mathrm{Ni}_{3}$ samples before and after cold rolling, as indicated. (b) Desorption kinetic curves after activation. (c) Absorption kinetic curves after the first cycle shown in (a) and (b).

The microstructure of the MS + CR $\mathrm{Mg}_{97} \mathrm{Ni}_{3}$ sample is certainly more homogeneous than the one that we have observed before for commercial $\mathrm{Mg}$ processed by $\mathrm{CR}^{11}$, in which fine grains or subgrains coexisted with a fraction of much larger grains. We attribute this behavior to the fine initial Mg grain size of the MS sample and also to a possible pinning effect due $\mathrm{Mg}_{2} \mathrm{Ni}$, which can be seen decorating the magnesium grains in Figure 3a, avoiding grain growth after dynamic recrystallization.

The observed microstructural refinement and [002] texture development, associated to the catalytic action of the $\mathrm{Mg}_{2} \mathrm{Ni}$ nanoparticles and to the high density of defects, which results from the processing by melt spinning and cold rolling, promotes attractive activation and $\mathrm{H}$-sorption properties, as shown in Figure 4.

As mentioned in Section 2, the $\mathrm{Mg}_{97} \mathrm{Ni}_{3}$ alloy ribbons were stored in air for seven years before being submitted to CR. Despite of this long time of air exposure, the MS samples could still be activated, but a long incubation time of 12.5 hours was observed. However, this incubation time could be eliminated by cold rolling, which also promotes faster activation, even if the incubation time is disregarded, Figure $4 \mathrm{a}$. For example, the capacity of $4.0 \%$ is reached after 15.7 hours in the MS + CR condition, but only after 31.8 hours in the MS one.

As shown in Figure 4b, c, the MS + CR sample presents much faster $\mathrm{H}$-sorption kinetics than the melt spun ribbons. In Figures 4b, the amount of hydrogen desorbed was normalized using the total capacity after the activation measurements. Hydrogen desorption kinetics is quite fast for both samples at $350^{\circ} \mathrm{C}$. For example, full desorption in the MS + CR was achieved in only 11 minutes, indicating that it is still possible decrease the desorption temperature but still keeping fairly high desorption rate.

Figures $4 \mathrm{c}$ shows the second cycle absorption kinetics of MS and MS + CR samples. As expected, the times involved to achieve high hydrogen capacities were substantially decreased after activation. In the case of the MS + CR sample, the time needed to reach $4.0 \mathrm{wt}$. (\%) of hydrogen capacity was reduced from 15.7 to 2 hours.

\section{Conclusions}

In the present study, the effects of cold rolling in $\mathrm{Mg}_{97} \mathrm{Ni}_{3}$ melt spun ribbons in terms of structure and hydrogen storage properties were investigated. Even after a prolonged air 
exposure of seven years, the ribbons could be properly activated, but in this case with a long incubation time of 12.5 hours at $350{ }^{\circ} \mathrm{C}$ and 20 bar of $\mathrm{H}_{2}$. Extensive cold rolling using stainless steel plates has been shown to be a viable procedure to the $\mathrm{Mg}$ alloy ribbons, producing cold welded laminated foils with thickness of around $100 \mu \mathrm{m}$.

A refined microstructure is obtained by melt spinning, consisting mainly of sub-micrometric Mg grains supersaturated with $\mathrm{Ni}$ and a fine dispersion of $\mathrm{Mg}_{2} \mathrm{Ni}$ nanoparticles. Cold rolling promotes a significant further grain refinement and increases by a large amount the density

\section{References}

1. Sakintuna B, Lamari-Darkrim F and Hirscher M. Metal hydride materials for solid hydrogen storage: a review. International Journal of Hydrogen Energy. 2007; 32:1121-1140. http:// dx.doi.org/10.1016/j.ijhydene.2006.11.022

2. Klyamkin SN. Metal hydride compositions on the basis of magnesium as materials for hydrogen accumulation. Russian Journal of General Chemistry. 2007; 77:712-720. http://dx.doi. org/10.1134/S1070363207040330

3. Liang G, Huot J, Boily S, Van Neste A and Schulz R. Catalytic effect of transition metals on hydrogen sorption in nanocrystalline ball milled $\mathrm{MgH}_{2}-\mathrm{T}_{\mathrm{m}}\left(\mathrm{T}_{\mathrm{m}}=\mathrm{Ti}, \mathrm{V}, \mathrm{Mn}, \mathrm{Fe}\right.$ and $\mathrm{Ni}$ ) systems. Journal of Alloys and Compounds, 1999; 292:247-252. http:// dx.doi.org/10.1016/S0925-8388(99)00442-9

4. Oelerich W, Klassen T and Bormann R. Metal oxides as catalysts for improved hydrogen sorption in nanocrystalline Mg-based materials. Journal of Alloys and Compounds 2001; 315:237-242. http://dx.doi.org/10.1016/S0925-8388(00)01284-6

5. Vaichere A, Leiva DR, Ishikawa TT and Botta WJ. Synthesis of $\mathrm{MgH}_{2}$ and $\mathrm{Mg}_{2} \mathrm{FeH}_{6}$ by reactive milling of $\mathrm{Mg}$-based mixtures containing fluorine and iron. Materials Science Forum. 2008; 570:39-44. http://dx.doi.org/10.4028/www. scientific.net/MSF.570.39

6. Varin RA, Li S and Calka A. Environmental degradation by hydrolysis of nanostructured $\beta-\mathrm{MgH}_{2}$ hydride synthesized by controlled reactive mechanical milling (CRMM) of $\mathrm{Mg}$. Journal of Alloys and Compounds. 2004; 376:222-231. http:// dx.doi.org/10.1016/j.jallcom.2003.12.040

7. Dufour J and Huot J. Rapid activation, enhanced hydrogen sorption kinetics and air resistance in laminated Mg-Pd 2.5 at.\%. Journal of Alloys and Compounds. 2007; 439:L5-L7. http://dx.doi.org/10.1016/j.jallcom.2006.08.264

8. Krystian M, Zehetbauer MJ, Kropik H, Mingler B and Krexner G. Hydrogen storage properties of bulk nanostructured ZK60 of defects. It also introduces a very strong [002] fiber type texture and causes $\mathrm{Mg}_{2} \mathrm{Ni}$ precipitation.

After cold rolling, no incubation time was observed during hydrogen activation. The combination of the benefits of rapid solidification (refined microstructure) and cold work (texture, additional refinement and introduction of defects) produces a material with attractive $\mathrm{H}$-sorption kinetics after activation. The results showed here prove that low cost mechanical processing, such as cold rolling, after an initial rapid solidification step is an attractive processing route for the synthesis of hydrogen storage materials.

$\mathrm{Mg}$ alloy processed by Equal Channel Angular Pressing. Journal of Alloys and Compounds. 2011; 509:S449-S455. http://dx.doi.org/10.1016/j.jallcom.2011.01.029

9. Léon A, Knystautas EJ, Huot J and Schulz R. Influence of the evaporation rate and the evaporation mode on the hydrogen sorption kinetics of air-exposed magnesium films. Thin Solid Films. 2006; 496:683-687. http://dx.doi.org/10.1016/j. tsf.2005.08.227

10. Leiva DR, Fruchart D, Bacia M, Girard G, Skryabina $\mathrm{N}$, Villela ACS et al. Mg alloy for hydrogen storage processed by SPD. International Journal of Materials Research. 2009; 100:1739-1747. http://dx.doi. org/10.3139/146.110225

11. Leiva DR, Huot J, Ishikawa TT, Bolfarini C, Kiminami CS, Jorge Junior AM et al. Hydrogen activation behavior of commercial magnesium processed by different severe plastic deformation routes. Materials Science Forum. 2011; 667-669:1047-1051. http://dx.doi.org/10.4028/ www.scientific.net/MSF.667-669.1047

12. Leiva DR, Jorge Junior AM, Ishikawa TT, Huot J, Fruchart D, Miraglia $\mathrm{S}$ et al. Nanoscale grain refinement and $\mathrm{H}$-sorption properties of $\mathrm{MgH}_{2}$ processed by high-pressure torsion and other mechanical routes. Advanced Engineering Materials. 2010; 12:786-792. http://dx.doi.org/10.1002/ adem. 201000030

13. Huot J. Measurement of $\mathrm{H}_{2}$ sorption properties. In: Hydrogen technology: mobile and portable applications. Berlin: Springer; 2008. p.471-500.

14. Bendersky LA, Chiu C, Skripnyuk VM and Rabkin E. Effect of rapid solidification on hydrogen solubility in $\mathrm{Mg}$-rich Mg-Ni alloys. International Journal of Hydrogen Energy. 2011; 36:5388-5399. http://dx.doi.org/10.1016/j. ijhydene.2011.01.133 